DOI: 10.1136/annrheumdis-2019-eular.3046

\section{THU0047 IA-14069, A NOVEL SMALL-MOLECULE INHIBITOR DIRECT-TARGETING TUMOR NECROSIS FACTOR- $\alpha$ ATTENUATES COLLAGEN INDUCED ARTHRITIS}

Sung-Dong Park ${ }^{1}$, Hyung Gun Maeng ${ }^{1}$, Yeon-Hwa Park ${ }^{2}$, Kye-Jung Shin ${ }^{1,2}$, TaeHwe Heo ${ }^{1,2}$. ${ }^{1}$ ILAb Inc., College of Pharmacy, The Catholic University of Korea, Bucheon, Korea, Rep. of (South Korea); ${ }^{2}$ The Catholic University of Korea, Integrated Research Institute of Pharmaceutical Sciences, College of Pharmacy, Bucheon, Korea, Rep. of (South Korea)

Background: Rheumatoid arthritis (RA) is systemic autoimmune disease that is characterized by autoreactive immune cells and various cytokinesmediated inflammation in multiple joints, leading to cartilage degradation, bone erosion and finally irreversible joint destruction ${ }^{1}$. The inflammatory cytokine tumor necrosis factor- $\alpha(\mathrm{TNF}-\alpha)$ is known to play a central role in several chronic immune-mediated inflammatory disorders ${ }^{2}$.

Objectives: Despite the great success of anti-TNF- $\alpha$ biological drugs in the treatment of RA, no chemical drug targeting TNF- $\alpha$ is available. Here we report that IA-14069, a novel small molecule inhibitor, binds directly to TNF- $\alpha$ and inhibits TNF- $\alpha$ activities both in vitro and in vivo.

Methods: IA-14069 was screened and identified by competitive binding assay using TNF- $\alpha$ and TNF receptor. In vitro neutralization activity of IA-14069 against TNF- $\alpha$ was determined using MTT assay. The direct binding IA-14069 to TNF- $\alpha$ was demonstrated by surface plasmon resonance and bead pull-down assays. The inhibition of TNF- $\alpha-T N F R$ interactions by direct binding of IA-14069 to TNF- $\alpha$ was analyzed by flow cytometry. Levels of phosphorylated $\mid \kappa B \alpha(p-I \kappa B \alpha)$ and $N F-\kappa B$ p65 were analyzed by western blot. IA-14069 was orally administrated to TNF- $\alpha$ transgenic (TNF- $\alpha-T G$ ) RA mice at 3.3 or $33 \mathrm{mg} / \mathrm{kg}$ twice per week or at 25,50 or $100 \mathrm{mg} / \mathrm{kg} 3$ times per week for preventive or therapeutic effect, respectively. In vivo therapeutic efficacy of IA-14069 or methotrexate was evaluated in collagen-induced arthritis (CIA) mice immunized with bovine type II collagen (CII) emulsified in complete Freund's adjuvant, and boosted with CII emulsified in incomplete Freund's adjuvant.

Results: IA-14069 potently inhibits both TNF- $\alpha$-induced cytotoxicity $\left(\mathrm{IC}_{50}<\right.$ $0.7 \mu \mathrm{M})$ which directly binds to TNF- $\alpha$ and TNF- $\alpha$-triggered signaling ( $p$ $I \kappa B \alpha$ and $N F-\kappa B$ p65) activities. The therapeutic as well as preventive anti-RA effects of IA-14069 were demonstrated in TNF- $\alpha$-TG and CIA models. IA-14069 and MTX had synergistic effects in the CIA therapeutic model. According to pharmacokinetic analysis, IA-14069 showed significant bioavailability. In addition, no in vivo toxicity was observed even under treatment of excessive amount of IA-14069.

A TNF-TG RA model: Preventive

B TNF-TG RA model: Therapeutic
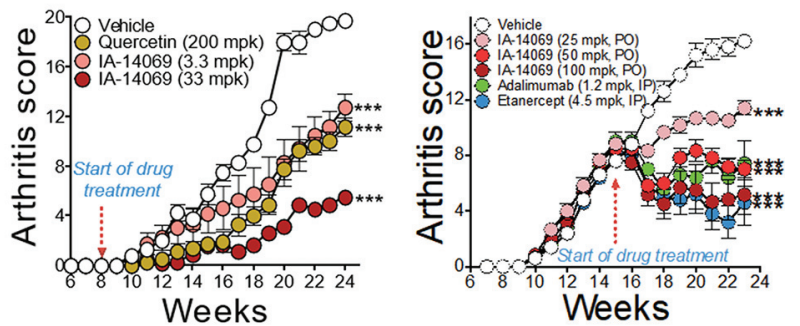

C CIA RA model: Therapeutic

\section{CIA RA model: Combination}

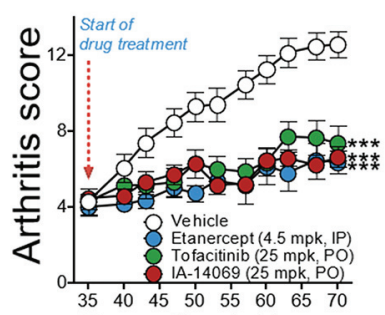

Days after $1 \mathrm{st}$ Imm.

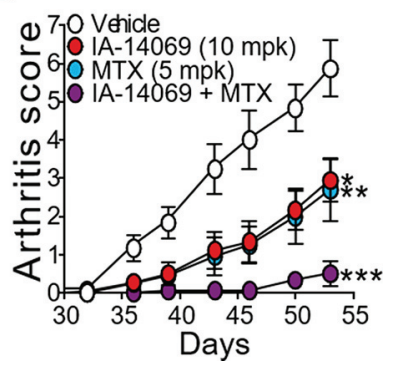

Abstract THU0047 - Figure 1

Conclusion: The data indicate that IA-14069 can be a novel and potential TNF- $\alpha$ inhibitor for the treatment of RA and other inflammatory diseases.
REFERENCES:

[1] Choy EH, et al. N Engl J Med. 2001;344:907-16.

[2] Wong M, et al. Clin Immunol. 2008;126:121-36.

Disclosure of Interests: Sung-Dong Park Employee of: MOGAM Institute for Biomedical Research, Hyung Gun Maeng: None declared, Yeon-Hwa Park: None declared, Kye-Jung Shin: None declared, Tae-Hwe Heo: None declared

DOI: 10.1136/annrheumdis-2019-eular.5478

\section{\begin{tabular}{|l|l}
\hline THU0048 & 2ND LINE TREATMENT WITH LESINURAD AND
\end{tabular} ALLOPURINOL VERSUS FEBUXOSTAT FOR MANAGEMENT OF HYPERURICEMIA: A COST- EFFECTIVENESS ANALYSIS FOR SPANISH PATIENTS}

María Presa ${ }^{1}$, Fernando Perez-Ruiz ${ }^{2}$, Itziar Oyagüez ${ }^{1} .{ }^{1}$ Pharmacoeconomics and Outcomes Research Iberia (PORIB), Madrid, Spain; ${ }^{2}$ Hospital Universitario Cruces, Rheumatology Division, Bilbao, Spain

Background: Lesinurad, a medication that inhibits uric acid reabsorption has been recently approved in combination for the treatment of patients with gout which do not reach therapeutic serum urate target with xanthineoxidase inhibitors monotherapy

Objectives: To assess the incremental cost-effectiveness ratio of adding lesinurad to allopurinol as $2^{\text {nd }}$ line therapy, compared to febuxostat for the management of patients with gout in Spain.

Methods: A Markov model comprising 6 health-states representing the disease evolution was used to estimate in 6-months cycles, the lifetime accumulated cost and benefits in terms of quality-adjusted-life-year (QALY) in an hypothetical cohort of patients stratified according to serum uric acid levels observed on pooled CLEAR trials: $18.8 \% \quad(<6 \mathrm{mg} / \mathrm{dL})$; $63.7 \%(6-8 \mathrm{mg} / \mathrm{dL}) ; 15.2 \%(8-10 \mathrm{mg} / \mathrm{dL})$ and $2.3 \%(\geq 10 \mathrm{mg} / \mathrm{dL})$. During the simulation, patients could either continue with $2^{\text {nd }}$ line treatment with lesinurad (200mg/daily) plus allopurinol (400mg/daily) or febuxostat $(80 \mathrm{mg} /$ daily), switch to allopurinol monotherapy (271mg/daily) in case of intolerance or discontinue treatment. Proportion of tophaceous gout (18.9\%) was considered at each health-state. The efficacy of treatments was captured in the transition probabilities between health states which were derived from findings on CLEAR 1, CLEAR 2 and EXCEL clinical trials. Quality of life related to gout severity (tophaceous or non-tophaceous) and flare frequency was considered by means of utilities estimated from SF-36 scores of the pooled CLEAR trials which were mapped to EQ-5D values. The total cost estimation $(€, 2018)$ included drug acquisition cost (retail prices with mandatory deduction applied), disease monitoring ( $€ 377.03$ for first 6-month period, $€ 329.95 /$ subsequent year) and flare management cost $(€ 301.69)$. Unitary costs derived from local cost databases and literature. A 3\% annual discount rate was applied for cost and outcomes. Sensitivity analyses (SA) were carried out.

Results: Lesinurad added to allopurinol provided higher QALYs (14.79) than febuxostat (14.69). Total accrued cost per patient were lower $(€$ $6,819.13$ ) with lesinurad and allopurinol ( $€ 49,659.27)$ compared to febuxostat $(€ 56,478.40)$. Lesinurad plus allopurinol resulted a dominant option (more effective and less costly) compared to febuxostat. SA results confirmed the model robustness.

Conclusion: These results suggest that treatment with lesinurad $200 \mathrm{mg} /$ day plus allopurinol $400 \mathrm{mg} /$ day compared to febuxostat $80 \mathrm{mg} /$ day is an effective second option for the management of hyperuricemia in patients with gout who did not reach therapeutic srum urate target to previous allopurinol monotherapy, associated to cost-savings for the Spanish National Health System.

\section{REFERENCES:}

[1] Bardin T, et al. Ann Rheum Dis. 2017;76:811-20.

[2] Becker MA, et al. J Rheumatol. 2009;36:1273-82.

[3] Pérez-Ruiz F, et al. J Med Econ. 2016;19:604-10.

[4] Saag K, et al. Arthritis Rheumatol. 2017;69:203-12.

Disclosure of Interests: María Presa Consultant for: I am employee of PORIB a consultant company which has received financial support from Grünenthal for development of this project, Fernando Perez-Ruiz Grant/ research support from: Cruces Rheumatology Association, Consultant for: Grunenthal, Menarini, Horizon, Speakers bureau: Menarini, Grunenthal; Spanish foundation for rheumatology, Itziar Oyagüez Consultant for: I am employee of PORIB a consultant company which has received financial support from Grünenthal for development of this project DOI: 10.1136/annrheumdis-2019-eular.3231 